\title{
(DES) ENCANTOS COM O COMUNITARISMO CULTURAL E A POLITICA DE RECONHECIMENTO DE CHARLES TAYLOR
}

\section{(DIS) ENCHANTMENTS WITH THE CULTURAL COMMUNITARIANISM AND CHARLES TAYLOR'S POLICY OF RECOGNITION}

Doglas Cesar Lucas

doglasl@unijui.edu.br

Recebido em: 15/05/2014

Aprovado em: 11/09/2014

Sumário: 1. Considerações iniciais. 2. Multiculturalismo: diferenças em busca de reconhecimento. 3. A clássica posição liberal sobre a universalidade dos direitos humanos. 4. Notas gerais sobre a posição comunitarista na defesa dos direitos culturais. 5. O comunitarismo de Taylor e sua política de reconhecimento. 6. Em defesa da interculturalidade dos Direitos humanos: sobre a necessidade de se superar o debate entre liberais e comunitaristas. 7. Considerações Finais. Referências.

\section{Resumo}

O presente texto pretende apresentar a proposta comunitarista de Taylor e o modo como o autor compreende a complexa e nem sempre amistosa relação entre os direitos humanos e o multiculturalismo. Aborda de forma geral as diferentes posições que assumem os liberais e os comunitaristas no enfrentamento dos problemas de igualdade e de diferença que caracterizam as demandas de identidade e de pertença cultural, para depois centrar a análise nas ideias de Taylor. Nas considerações finais são criticadas algumas posturas comunitaristas de Taylor e sustentada uma visão intercultural de direitos humanos capaz de denunciar as fragilidades da concepção abstrata de homem do liberalismo e o relativismo cultural que justifica tipos diferentes de dominação e exclusão.

\begin{abstract}
:
The present text intends to submit Taylor's communitarian proposal and the way the author understands the complex and not always friendly relation between human rights and multiculturalism. It approaches in a general way the different positions that liberals and communitarians assume on facing equality and difference problems that feature the identity and cultural belonging demands, and then center the analysis on Taylor's ideas. On the final considerations, Taylor's communitarianist exaggerations are criticized and a intercultural view on human rights is supported, which is capable of denouncing the fragilities of the abstract conception of the liberalism's man and the cultural relativism that justifies different kinds of domination and exclusion.
\end{abstract}




\section{Palavras-chave:}

Direitos humanos; liberalismo; comunitarismo; interculturalidade; Charles Taylor; multiculturalismo; reconhecimento

\section{Keywords:}

Human rights; liberalism; communitarianism; interculturalism; Charles Taylor; multiculturalism; recognition.

\section{Considerações iniciais}

Apesar de nunca ter saído de cena, o problema teórico e prático dos direitos humanos adquire peculiar importância no contexto da sociedade global. Novas formas de produção da sociabilidade dão visibilidade a problemas que estavam encobertos ou atenuados pelas cortinas conceituais modernas e pela limitação de uma teoria jurídica refém das epistemologias positivistas.

Em uma sociedade que se complexifica, que reconstitui suas modalidades de produção de identidade e de pertença e que promove um permanente encontro entre culturas diversas, é inevitável que se estabeleça um dialético enfrentamento entre um projeto universal de Direitos Humanos e as múltiplas realidades culturais. Não que o problema do multiculturalismo seja novo. É apenas uma realidade que se percebeu de forma mais substancial com o processo global de produção, operado a um só tempo, o da sociabilidade e da barbárie. A globalização provoca justamente este fenômeno de radicalização da visibilidade identitária, de aproximações e de afastamentos, de centralizações e descentralizações, de valorização do local e do global a um só tempo. As culturas locais ganham importância no processo de produção de identidade em um mundo que processa ondas de homogeneização. Nesse sentido é importante evitar que o pluralismo cultural ou mesmo o universalismo uniformizador justifiquem denegações e construam novos fundamentalismos, capazes de fragilizar a capacidade emancipadora dos Direitos Humanos pelos relativismos produtores e defensores de qualquer tipo de sociabilidade.

Nesse cenário de encontros e desencontros culturais, tanto a universalidade dos direitos humanos quanto a particularidade das diferenças são questionadas e se questionam mutuamente. Alternativas interculturais, por sua vez, têm ecoado mais acordos teóricos do que práticos. Enquanto os liberais defendem a centralidade do indivíduo e a igualdade das diferentes concepções de bem, Taylor aposta na comunidade e sua capacidade de fundar sentidos prévios ao indivíduo como sujeito cultural. Ao inaugurar uma agenda para a temática multicultural centrada no protagonismo da comunidade e nas críticas ao liberalismo, sua proposta teórica acabou, mesmo que de forma indireta, abrindo caminho para se questionar a universalidade dos direitos humanos e para reafirmar relativismos e a legitimidade de histórias culturais localistas. O presente texto pretende apresentar, em notas gerais, a proposta comunitarista de Taylor e o modo como o autor compreende a complexa e nem sempre amistosa relação entre os direitos humanos e o multiculturalismo. Nas considerações finais são criticados os exageros da proposta comunitarista de Taylor e sustentada uma visão 
intercultural de direitos humanos capaz de denunciar as fragilidades da concepção abstrata de homem do liberalismo e o relativismo cultural que justifica tipos diferentes de dominação e exclusão.

\section{Multiculturalismo: diferenças em busca de reconhecimento}

Segundo Bhikhu Parekh (2000) as sociedades multiculturais modernas diferenciam-se das sociedades multiculturais pré-modernas em quatro aspectos. Primeiro, porque nas sociedades pré-modernas as comunidades minoritárias mantinham-se reclusas nos exatos limites definidos pelos grupos dominantes, aceitando uma posição de subordinação. Nas sociedades modernas - melhor seria se dissesse “contemporâneas" -, a aproximação entre as culturas, resultado da dinâmica do processo de globalização, é praticamente inevitável, e graças aos ideários democráticos e liberais, mesmo as comunidades culturais ditas inferiores passaram a exigir igual direito de reconhecimento e participação. A segunda distinção mencionada pelo autor é tributada ao melhor entendimento que as sociedades modernas possuem em relação aos males que o dogmatismo moral pode provocar. Para o autor, a importância da cultura na formação do sujeito foi assimilada pela sociedade, que passou a respeitar as diferenças culturais e considerar a cultura como uma categoria política relevante. Como terceiro aspecto é apresentada nova conformação mundial no campo econômico, cultural e tecnológico, que tem ampliado o contato entre todas as partes do mundo e acabado por completo com o isolamento das culturas. Por fim, o autor refere como uma característica marcante das sociedades multiculturais contemporâneas as transformações que têm afetado o Estado-nação culturalmente homogeneizador.

Ainda de acordo com Parekh, o multiculturalismo, como processo de reivindicação identitária, iniciou-se por volta dos anos de 1960, quando foi reconhecido pela mídia mundial o movimento popular norte-americano denominado "Panteras Negras". Esse movimento exigia o reconhecimento da situação peculiar das minorias de afrodescendentes nos Estados Unidos da América, dado que a formação da população desse país, embora tendo envolvido a emigração em massa de contingentes oriundos de diversas partes do globo, nunca abandonou 
a necessidade de respeito a um sentimento maior de "americanismo", largamente reproduzido pelos meios de ensino e comunicação. O movimento apoiou-se nos próprios instrumentos político-democráticos desse Estado, que possibilitam a livre manifestação do pensamento, para exigir o respeito à condição de diferença dos cidadãos dessa etnia que, em sua maioria, não contavam, como acontecia então com a elite europeizada, com instrumentos de acesso equânime a serviços públicos mais avançados, como as universidades. O movimento dos "Panteras Negras" logo foi seguido por outros de equivalente poder de captação, não menos conhecidos mundialmente, como o feminismo ou o movimento homossexual. Os movimentos multiculturalistas aumentaram com a queda do muro de Berlim, evento após o qual todas as sociedades do bloco comunista passaram a conviver com reclamações por respeito às diferenças, especialmente étnicas - e a questão da Bósnia talvez seja o mais sensível desses casos.

O que todos esses movimentos tinham em comum era a necessidade de reconhecimento de suas diferenças culturais. Não desejavam - salvo em casos bem pontuais - que as especificidades de sua própria cultura suplantassem definitivamente o ideal nacional já estabelecido, ou mesmo que seus membros fossem considerados apartados do cenário cultural do Estado-nação. Apenas desejavam ser reconhecidos dentro da nação à qual pertenciam, como portadores de características particulares que os diferenciavam da população ainda adstrita à ideia de cidadania nacional. De fato, quando o Estado identifica todos os indivíduos sob o pálio da cidadania nacional, ignora as diferenças políticas, sociais e econômicas que afetam a manifestação de sua vida material. A igualdade jurídicopolítica dos cidadãos impede ao Estado considerar os cidadãos de forma especial, como portadores de características diferenciadas, nem piores, nem melhores - ou pior, faz até mesmo esquecer que tais diferenças existem. Essa "nivelação por baixo", fundada na ausência de políticas efetivas de promoção de um espaço público de aceitação e convivência entre as particularidades, faz com que se percam potencialidades individuais e coletivas, agindo justamente em desfavor da necessidade de preservação daquilo que é capaz de produzir a identidade e o sentimento de pertença (SEMPRINI, 1999).

Para Semprini (1999) o multiculturalismo revela os paradoxos da contemporaneidade, especialmente ao exigir que seus postulados de 
universalidade, de igualdade e de justiça sejam estendidos para todas as formas de manifestação cultural. A democracia moderna, calcada na ideia de sujeitos universais e na negação das identidades particulares, é desafiada pelo multiculturalismo na medida em que suas reivindicações têm em vista direitos que parecem dificilmente universalizáveis. Do ponto de vista do direito à diferença, conclamado pelo multiculturalismo, os ideais humanos universais seriam uma nova tentativa de homogeneização, tal como já verificado anteriormente com o processo de nacionalização do ente cultural. O conflito, então, estabelece-se entre a necessidade de preservação das culturas dos diferentes povos e o dever de observância aos direitos do homem indistintamente entre esses grupos de indivíduos, enveredando, muitas vezes, para a relativização. Danilo Martuccelli (1996) refere que, com o multiculturalismo, a ideia de igualdade universal, que desconsiderava as diferenças, foi substituída pela concepção de equidade, caracterizada pelo reconhecimento das especificidades culturais dos indivíduos e dos grupos e pela possibilidade de um tratamento diferenciado para os membros dessas mesmas coletividades. Do mesmo modo, continua o autor, com o multiculturalismo surge, da fusão entre liberdade negativa e liberdade positiva, a ideia de diferença como um direito individual de identidade, de autenticidade, de pertença a um grupo.

Se por um lado a pluralidade cultural é uma realidade e uma virtude das sociedades democráticas que devem ser estimuladas. Por outro, o facilitado encontro das diferenças na sociedade global expôs, também, divergências e irritações que não favorecem o diálogo intercultural e que, não raras vezes, demarcam com agressividade o nível das oposições e afastamentos (OLIVÉ, 1999). Por isso, pode-se dizer que as demandas por reconhecimento das identidades culturais desafiam duplamente os direitos humanos, pois, ao mesmo tempo em que são requisitados para garantir o direito de cada cultura particular manifestar sua concreta historicidade e desenvolver seus laços identitários, os direitos humanos, entretanto, são considerados como exigências recíprocas de abrangência universalista, que não condicionam seus fundamentos e sua validade a nenhuma experiência cultural específica. Assim, o fato de diferentes culturas postularem o mesmo direito de exercerem, em um mesmo país, as suas diferenças, exige dos direitos humanos uma espécie de mediação entre a igualdade e a diferença que sua universalidade comporta (ALCALÁ, 2005; TORRE, 2000). 


\section{A clássica posição liberal sobre a universalidade dos direitos humanos}

O enfrentamento dos problemas culturais pela postura liberal não produziu uma teoria hermética a respeito do tema. São encontradas posições liberais mais abertas, outras mais fechadas, mas todas conduzem sua análise a partir de pressupostos que podem ser agrupados em único formato de abordagem. Sustentam os liberais que uma sociedade marcada por diferentes valores e por individualidades em conflito será mais bem ordenada quando todas as concepções de bem forem igualmente consideradas e quando nenhuma delas se sobrepuser às demais. Uma sociedade, aduz Rawls (2000) - depois de sofrer críticas comunitaristas ao conceito de pessoa abstrata e do véu da ignorância -, diferentemente de uma comunidade ou associação (que tem uma estrutura fechada e é auto-suficiente, como é o caso da vida religiosa), não apresenta fins e objetivos pré-determinados no que tange à eleição material de uma determinada concepção de bem, senão que compartilha de um objetivo comum no que se refere à definição de uma justiça política que consiga promover a cooperação social entre todos os cidadãos, inclusive de gerações diferentes, pela adoção de procedimentos e de instituições justas e pela valorização de todos os cidadãos como pessoas iguais e livres. (ALTABLE, 1995).

Uma característica determinante do entendimento liberal é o papel de centralidade atribuído ao indivíduo na formação da sociedade. A qualidade da pessoa, de sua autonomia, é anterior a qualquer fim. O homem é prévio a todo tipo de experiência histórica, não dependendo sua moralidade de vinculações de cunho social, político ou religioso (LA FUENTE, 2005). O homem tem sua dignidade amparada na sua natureza moral, na humanidade que lhe é inerente. Os vínculos identitários que possa estabelecer ao longo de sua vida não são determinantes e contingentes para a definição do que o homem é enquanto sujeito moral que deve ser protegido. O ser humano é um ser moral dotado de sentimento de justiça e capaz de estabelecer seus projetos de vida de modo autônomo, uma vez que pode atuar de acordo com princípios universais, com os quais os homens estariam de acordo como seres racionais, livres e iguais. Em outras palavras, o homem pode racionalmente fazer julgamentos morais que não decorrem de uma pauta específica de valores, mas de princípios universais que são reconhecidos 
para além de conceitos históricos, econômicos, culturais, religiosos, etc (BICK, 1995).

Isso não quer dizer que o liberalismo se oponha à pluralidade de formas de vida. Antes pelo contrário, reconhece que todos os homens, livres e iguais, devem conduzir seus projetos de vida, levando em conta as suas inclinações e respeitando o mesmo direito para todos os outros homens. Os direitos, nesse sentido, servem para garantir a todos os homens o exercício de sua liberdade, de sua autonomia. São direitos do indivíduo como tal, que não podem ser afastados ou mitigados para preservar ou proteger a especificidade de uma cultura ou religião, por exemplo. Os direitos são essenciais aos indivíduos como seres humanos, não importando os vínculos que eles possam ter, e estão sustentados em sua autonomia moral. Os indivíduos possuem esses direitos, qualquer que seja a situação social, política ou religiosa em que conduzam sua existência. "Son universales en cuanto a su origen e idealmente universales en cuanto a su aplicación" (BICK, 1995, p. 82).

Quando o liberalismo estabelece uma prioridade do justo sobre as concepções de bem, é inevitável que tenha que reconhecer também a neutralidade do Estado sobre as concepções de bem de seus cidadãos. A esfera pública, nesse caso, não pode se imiscuir nas deliberações privadas dos indivíduos. O Estado deve assegurar a todos os cidadãos iguais oportunidades para promover as concepções de bem livremente formuladas, desde que, segundo Rawls (2000), estejam de acordo com os princípios de justiça. Da mesma forma, o Estado deve abster-se de estimular uma determinada concepção de bem em detrimento de outras, sendo desaconselhável reconhecer condições específicas para que um tipo de noção de bem se realize de forma mais favorável. Por isso, o Estado não deve interferir demasiadamente na vida de seus cidadãos, senão para garantir os meios necessários para que cada um possa realizar de forma satisfatória seus projetos pessoais de vida (VITALE, 2000; OLSEN, 2004).

Naturalmente, nenhum laço ou vínculo identitário pode exercer um papel de protagonista na definição do bem de cada indivíduo, a ponto de exigir dele um respeito incondicional e o reconhecimento para além dos seus direitos individuais. Não cabem nas leituras liberais, notadamente nas mais fechadas, as demandas das minorias culturais exigindo a titularidade coletiva de direitos. Não é a cultura em si mesma que deve ser protegida, mas os direitos que todos os seres humanos possuem de 
se vincularem livremente a uma cultura ou de abandoná-la. Ao proteger o indivíduo moralmente considerado, o liberalismo propõe uma agenda universal de valores que se opõe a qualquer tipo de ataque organicista, seja estatal ou comunitário. Nesse sentido, o liberalismo coloca-se de forma antagônica às pretensões particularistas que povoam as exigências da versão comunitarista do multiculturalismo (RUIZ, 2005).

\section{Notas gerais sobre a posição comunitarista na defesa dos direitos culturais}

Não obstante a especificidade presente nos diferentes autores comunitaristas, pode-se afirmar que todos eles convergem na direção de uma crítica ao liberalismo, a ponto dessa crítica ser ela mesma o fio convergente dessa corrente teórica. Reprovam a tese liberal que sustenta a noção de sociedade como um agrupamento de indivíduos, cada qual com sua concepção de vida boa, que são movidos por interesses e objetivos individuais e que possuem direitos que se sobrepõem e têm prioridade total frente a qualquer tipo de demanda comunitária. Para os comunitaristas - e isso está bem caracterizado em Taylor (2000) -, defender a tese liberal é olvidar que os laços de pertença com a comunidade é que dão sentido à vida do indivíduo, uma vez que é pela relação dialogal, realizada na comunidade com os outros semelhantes, que a identidade cultural é forjada e que os vínculos de lealdade para com o grupo se tornam compreensíveis e indispensáveis para a reciprocidade, para a manutenção da própria comunidade e, conseqüentemente, para a consciência de si como sujeito dependente de cultura (PINILLA, 1997).

Com efeito, os comunitaristas discordam do conceito de pessoa elaborado pelo liberalismo igualitário, pois alegam que, na definição do sujeito abstrato de direitos, não são consideradas as condições sociais nas quais esse mesmo sujeito exerce sua capacidade de autodeterminação que o caracteriza enquanto sujeito moderno (MIGUEL, 1992). O sujeito moral dos liberais seria artificial, desconectado da realidade social. Da mesma forma, o comunitarismo não aceita a tese liberal que reconhece o indivíduo como tal, independentemente do vínculo cultural, religioso, ou outra ligação de pertença, como sujeito capaz de questionar e de definir, por si só, os fins de sua relação com o mundo, a ponto de, inclusive, avaliar a possibilidade de continuar ou não a pertencer a uma determinada 
comunidade. Para os comunitaristas, os valores de uma comunidade não são eleitos isoladamente pelo indivíduo, mas são descobertos e reconhecidos durante o processo de pertencimento que se desenvolve em um grupo social. A identidade é anterior à escolha dos fins, aduz Sandel (2005). É a comunidade que tem prioridade sobre o indivíduo, pois é somente nela e a partir de suas valorações que o homem pode ter uma identidade; tão somente por ela o homem é capaz de compreender que os seus valores são decorrentes das relações comunitárias e que a proteção de ditos valores é, também, a proteção de sua identidade pessoal (SANCHÉS-CÁMARA, 1998).

Apesar do próprio MacIntyre (2001) afirmar que se distancia do comunitarismo, sob o argumento de que não está oferecendo um remédio para os males da sociedade como um todo, é evidente que nas suas críticas ao liberalismo está manifesta a importância da comunidade na definição das pautas morais (DÍAZ, 2001). De acordo com o autor, somente inserido no contexto social, cultural e histórico, o homem define-se, cumpre seu papel, seu telos. Ser homem é cumprir com determinados papéis, cada qual com propósito específico. Por isso, a pertença a uma comunidade é requisito indispensável para toda a ideia de bem, uma vez que as virtudes se encontram vinculadas às atividades humanas cooperativas, estabelecidas socialmente mediante a realização dos bens que lhe são inerentes. Os juízos morais são juízos fáticos, pois as regras de moralidade somente fazem sentido em razão da específica maneira como o homem vive sua própria história; os dados de uma vida, as particularidades morais engendradas pela família, bairro, cidade, tribo, país, etc., produzem o ponto de partida para a descoberta da identidade moral. É importante notar, porém, segundo Ignácio Sanchéz-Cámara (1998), que MacIntyre não está preocupado em impor o comunitarismo ao Estado, como tampouco apostar em um tipo de modelo comunitário, senão que pretende recuperá-lo nas instâncias coletivas menores, como na universidade, na igreja e em outras "aldeias".

O homem não pode eleger um bem se não tiver identidade e não pode ter identidade sem pertencer a uma comunidade; logo, não pode eleger uma noção de bem fora da comunidade (DÍAZ, 2001). Desse modo, não é possível conhecimento e avaliação ética fora dos próprios marcos de moralidade de cada comunidade (MASSINI CORREAS). A fonte exclusiva de moralidade são as tradições e os hábitos sociais aos quais está vinculado o sujeito, restando prejudicada a formação de 
conceitos universais de justiça e de moral. Por isso, afirma MacIntyre, nenhuma teoria foi capaz de fundamentar os direitos humanos racionalmente, pois tais direitos não passam de ficções que fracassam ao submetê-los a um critério moral objetivo e impessoal. Uma vez que a incomensurabilidade moral é fruto de um contexto histórico particular e não de uma moralidade universal, acreditar nos direitos humanos como direitos da pessoa enquanto tal, como diziam os filósofos do século XVIII, é o "mesmo que acreditar em bruxas e unicórnios" (MACINTYRE, 2001a, p.127).

Também não é aceita pelos comunitaristas a tese liberal de que o Estado deve agir de forma neutra diante das diferentes concepções de bem existentes em uma dada comunidade, garantido igual tratamento para todas elas e evitando a sobreposição de uma concepção específica de bem. Aduzem que é um equívoco defender a neutralidade do Estado, pois não é possível se escapar de todos os efeitos do condicionamento ao qual está submetido. É uma ilusão liberal que tenta negar o que não pode ser negado: todas as organizações políticas estão sempre referenciadas por um conjunto de valores (SANDEL, 2005). Os pontos de partida liberal, diz MacIntyre (2001b, p. 371), "não são nunca neutros no que se refere às concepções do bem humano; eles são sempre pontos de partida liberais". Além do mais, essa pretendida neutralidade impede que se estabeleçam laços de solidariedade entre os membros de uma mesma coletividade, bem como míngua a possibilidade de se definir um bem comum a ser alcançado. A falta de um projeto compartilhado e a liberação moral dos indivíduos tornam o liberalismo uma tendência moralmente anêmica. Por isso, apregoam os comunitaristas que, em vez de se manter afastado, o Estado deve auxiliar os indivíduos a se identificarem com determinadas formas de vida comum; deve ser ativista e reconhecer direitos para as culturas coletivamente consideradas, como forma de garantir a sobrevivência das condições de possibilidade para o reconhecimento que se dá em razão direta com os vínculos de pertença mantidos com uma dada comunidade.

Não obstante o próprio Michael Walzer (2003) situa sua posição teórica no liberalismo, ele considera que o liberalismo precisa de uma periódica correção comunitarista. Preocupado em elaborar uma teoria de justiça distributiva, o autor, tendo como cenário a comunidade política, parte da noção de que a existência de diferentes bens em uma comunidade exige a conformação de distintas esferas de justiça, cada qual 
com seus princípios de distribuição, os quais são devidamente orientados de acordo com os bens que lhe são afeitos. Bens distintos são tratados por esferas distintas, respeitadas as particulares de cada comunidade e os princípios próprios de distribuição para cada tipo de bem. Tais diferenças resultam das inúmeras maneiras de se compreender os bens sociais, decorrência inerente à diversidade histórica e cultural. Com isso, o autor quer dizer que "os princípios da justiça são pluralistas na forma; que os diversos bens sociais devem ser distribuídos por motivos, segundo normas e por agentes diversos; e que toda essa diversidade provém das interpretações variadas dos próprios bens sociais - o inevitável produto do particularismo histórico e cultural" (WALZER, 2003, p. 5).

O valor dos bens decorre da comunidade, é um atributo que se desenvolve nas relações compartilhadas que diferem de grupo para grupo e de época para época. "Os significados sociais são históricos em caráter; portanto, as distribuições, e as distribuições justas e injustas, mudam com o tempo" (WALZER, 2003, p. 9). Cada cultura tem o seu entendimento sobre os bens sociais. Os homens produzem cultura e atribuem sentido compartilhado para as coisas, para os bens que valorizam. Desse modo, faz-se justiça quando são respeitadas as criações de cada particularidade, pois a justiça, antes de ser um conceito que valha universalmente, deve ser encontrada nas distintas experiências e locais que constituem o modo de vida compartilhado. Não existe, portanto, um conceito unívoco de justiça. Por isso, não existe uma distribuição absolutamente justa dos bens. Dependerá sempre, sua justiça ou injustiça, dos significados atribuídos aos bens a que se refere. Os critérios de justiça estão condicionados pela realidade social, pelos significados sociais elaborados para cada bem. Por essa razão, pode-se concluir que a diferença entre os homens não é necessariamente injusta em si mesma, mas, ao contrário, é natural. O que deve ser evitado não são as diferenças, mas o exercício do domínio, de um homem sobre outro, pela apropriação de um dado bem social. Portanto, defende Walzer, em vez da igualdade simples, de matiz distributiva, é preferível uma igualdade complexa, que supõe uma diversidade de critérios de distribuição, os quais refletem a diversidade de bens sociais existentes e a diversidade de compreensões particulares a seu respeito.

Ao tratar especificamente da questão multicultural, parece que Walzer (1998), apesar de não se afastar de todo da tese central do comunitarismo, acena para a possibilidade de uma escolha liberal não ser 
necessariamente contrária à proteção das particularidades culturais. $\mathrm{O}$ autor cita que existem, no argumento do próprio Taylor, duas tendências universalistas que orientam as democracias liberais para distintas direções políticas. Entre os dois tipos de liberalismo apresentados por Taylor, o primeiro tipo (Liberalismo 1) está comprometido com a defesa dos direitos individuais de forma neutra, sem proteger ou beneficiar nenhum projeto cultural ou religioso. O outro tipo de liberalismo, denominado por Walzer (1998, p. 121) de Liberalismo 2, "permite um Estado comprometido com a sobrevivência e o florescimento de uma determinada nação, cultura ou religião, ou com um grupo (limitado) de nações, culturas e religiões - desde que os direitos básicos dos cidadãos que têm diferentes compromissos ou que não têm nenhum estejam protegidos". Para Walzer, o multiculturalismo pode conviver com o liberalismo de um Estado neutral que, entretanto, reconheça a igualdade das diferentes culturas. Por isso ele manifesta sua preferência pelo liberalismo de tipo 1, desde que escolhido de dentro do liberalismo de tipo 2. Ou seja, a escolha não é dirigida por um compromisso com um Estado neutro e protetor dos direitos individuais, mas é "governada pela condição social e pelas escolhas de vida actuais destes homens e mulheres" (WALZER, 1998, p. 121).

A constatação da multiplicidade de tradições culturais serve de base para a crítica relativista da impossibilidade de uma formulação universal de direitos. Amparados em um ponto de vista antropológico, que considera a pluralidade cultural como um fato inegável da existência humana, postulam que, para além das diferenças, deve-se fazer um esforço para encontrar o ponto de convergência em que todas as culturas se conectam, o ponto de interculturalidade que é o único capaz de ser considerado como universal. Dito de maneira mais específica, para os comunitaristas a universalidade homogeneíza, acaba com as diferenças tão importantes que dão significado à vida de cada membro da comunidade; ela desconsidera os elementos reais de solidariedade e sustenta-se em uma ideia abstrata de sujeito que não existe em nenhum lugar (SORIANO, 2004). Os comunitaristas defendem que não é possível uma fundamentação universal dos direitos humanos, razão pela qual, não sendo possível identificar laços de aproximação entre os direitos universais e as culturas específicas, não haveria necessidade de reconhecê-los. 


\section{0 comunitarismo de Taylor e sua política de reconhecimento}

A ideia central do pensamento de Charles Taylor (1998) é a de que o homem precisa da comunidade para se realizar, para encontrar uma pertença que se constitui pela relação com os "outros-importantes". A identidade depende das relações dialógicas com os demais membros da coletividade; não existe "eu" que possa ser elaborado fora da comunidade (TAYLOR, 1997). Somente pelo diálogo que mantém nela, o indivíduo consegue abastecer-se de elementos compreensivos necessários para exercer plenamente a sua existência. Arte, linguagem, gestos, amor, e todos os outros modos de expressão que permitem ao homem viver sua individualidade, somente são alcançados por ele quando inserido numa dada comunidade.

Ao contrapor um liberalismo defensor de uma política de igual dignidade, baseada no reconhecimento das capacidades universais e na negação da diferença, a um liberalismo que defende o direito de reconhecimento das diversas culturas, Taylor (2000) se posiciona favoravelmente a esse último, por considerar que cada cultura tem um valor em si mesma que não pode ser transladado para outras culturas, e que as especificidades de cada uma são fontes de produção de identidades. A igualdade é abstrata, mas o pluralismo e a diversidade fazem parte de um mundo de possibilidades reais. Portanto, segundo Taylor, é fundamental que se proteja a comunidade, que se reconheça a diversidade e o valor de todas as culturas, pois o não-reconhecimento das realidades culturais específicas enseja danos significativos na formação das identidades individuais e é a principal razão das disputas multiculturais contemporâneas (SANCHÉS-CÁMARA, 2007; MALDONADO, 2006).

Muito embora os opositores do multiculturalismo afirmem que a sua ameaça aos sistemas políticos democráticos reside na anulação do indivíduo no interior do grupo e na decisão desse grupo manter sua identidade particular e integrar uma ordem superior, Taylor demonstra o liame estrutural existente entre o desenvolvimento do individualismo e a reivindicação cultural a partir da ideia de reconhecimento e da categoria "eu dialógico".

Segundo Taylor (1998), a identidade do indivíduo vai se formando pelo contato com o outro, por meio de uma troca contínua que permite que o sujeito se defina e se estruture pela comparação e pela diferença, ou seja, na medida em que interage com os demais, com o outro-diferente, 
constitui-se como sujeito. As experiências sociais determinam a sua capacidade de reconhecimento como indivíduo e uma percepção de si mesmo, sendo a individualidade dependente das qualificações vistas nas interações com os outros, pois a 'consciência de si' só existe numa estrutura dialógica.

A teoria intersubjetiva do indivíduo reconhece o enraizamento e a pertença como noções importantes para construção do eu, isto é, da identidade individual que se forma pela educação e pela aprendizagem. O reconhecimento cede ao indivíduo um conjunto de valores e normas de conduta que lhe permite compreender o mundo e o 'eu' inserido. A valorização da diferença permite ao indivíduo distanciar-se de sua identidade e dispor de opções, como uma condição de emergência da identidade e da responsabilidade individual.

De acordo com Taylor, o desafio multicultural e a política de reconhecimento manifestam-se precárias nas sociedades democráticas liberais, empenhadas na universal e abstrata representação igualitária de todos e despreocupadas com as particularidades históricas de cada cultura. As instituições públicas são criticadas por não reconhecerem ou respeitarem as diferentes identidades culturais, principalmente os nativos, afrodescendentes, mulheres e latinos. Os Estados devem prestar auxílio aos grupos que têm dificuldades de preservarem suas culturas contra a penetração da dominação majoritária. Para reconhecer e tratar certos grupos como iguais, as instituições públicas precisam admitir as suas especificidades culturais, insiste o filósofo canadense.

Charles Taylor (1998) refere o conceito de identidade como sendo a maneira que uma pessoa se define e como as suas características fundamentais fazem dela um ser humano. Alerta, ainda, para o fato de que o não reconhecimento ou o reconhecimento precário dos indivíduos pode prejudicá-los ou reduzi-los a uma imagem limitada e distorcida, de desprezo ou inferioridade de si mesmos. Para ilustrar, menciona os exemplos da sociedade patriarcal, na qual as mulheres eram induzidas a adotarem uma opinião depreciativa de si mesmas, restando condenadas a uma postura de aviltamento de sua autoestima. No mesmo sentido, comenta sobre o fato de a sociedade branca europeia ter adotado uma imagem depreciativa dos negros, dos nativos e dos povos colonizados, tratando-os como incivilizados, desprezando-os e desrespeitando-os.

Tratando do nascimento da ideia de reconhecimento e de identidade, Taylor destaca o desaparecimento das hierarquias sociais 
que fundamentavam a antiga noção de honra e sua substituição, na modernidade, pela noção de dignidade universal e igualitária, baseada na perspectiva de reconhecimento moral do homem como homem. A política de reconhecimento introduzida pela democracia, que reivindica um estatuto igualitário para os sexos e para as culturas, adquiriu maior importância com a nova compreensão de identidade individualizada e com o ideal de autenticidade (TAYLOR, 1998).

No entanto, alerta Taylor, as diferenças entre os indivíduos e os grupos auferem importância moral e são determinantes na composição do ideal de autenticidade. Esse ideal de autenticidade fragiliza a identificação determinada pela posição social, visto que a maneira original do sujeito não pode ser um produto da influência de uma sociedade hierárquica. A estreita relação entre identidade e reconhecimento só poder ser compreendida se considerarmos o aspecto determinante da condição humana que é o seu caráter fundamentalmente dialógico. Quando adquirimos linguagens de expressão ricas em significados nos tornamos aptos a definirmos as nossas identidades (TAYLOR, 1997).

Embora não seja uma condição plena da definição do sujeito enquanto tal, a relação do indivíduo com os outros é importante para que ele possa se realizar. Charles Taylor entende a identidade como aquilo que nós somos em um determinado local, salientando que ela é o ambiente no qual as nossas opiniões e aspirações fazem sentido. A identidade que cultivamos depende das nossas relações dialógicas com os outros, por isso o desenvolvimento de um ideal de identidade gerada em nosso interior atribui uma nova importância ao reconhecimento. Nesse sentido,

a importância do reconhecimento é universalmente admitida, de uma forma ou de outra: no plano íntimo, estamos todos conscientes de como a identidade pode ser formada ou deformada no decurso da nossa relação com os outros-importantes; no plano social, temos uma política permanente de reconhecimento igualitário. Ambos os planos sofreram a influência do ideal de autenticidade, à medida que este foi amadurecendo, e o reconhecimento joga um papel essencial na cultura que surgiu à volta desse ideal. (TAYLOR, 1998, p. 56).

Em nível intimista, a formação da identidade do ser faz parte do diálogo e das lutas permanentes com os outros, enquanto que na esfera 
pública a noção das identidades se forma pelo diálogo e contribui ao desempenho de um papel crescente para a política do reconhecimento igualitário. Essa política refere-se à valorização da dignidade em vez da honra, bem como se refere ao desenvolvimento de uma noção moderna de identidade, a qual originou uma política de diferença, calcada no reconhecimento do caráter singular de cada um. Taylor afirma que a política da diferença colabora para o aumento das denúncias de discriminação e de recusa da cidadania. Todavia, as exigências de igualdade dificilmente são assimiladas na política de dignidade, uma vez que acarreta seja reconhecida a importância e o estatuto de algo não universalmente comum. Quer dizer, só reconhecemos aquilo que existe universalmente, peculiar a cada um. Entretanto, como todos possuem uma identidade, uma exigência universal estimula o reconhecimento das especificidades.

A política da dignidade universal objetivava a não discriminação, ignorando as distinções entre os indivíduos, ao passo que a política da diferença se redefine como uma exigência a fazer das distinções a base para o tratamento diferencial. Muito embora sejam diferentes, existem tentativas de se estabelecer um meio termo como medidas para melhorar a situação das minorias, como por exemplo, a discriminação positiva na vantagem competitiva aos menos favorecidos. Segundo a política da dignidade universal, todos os cidadãos são igualmente dignos de respeito. $O$ potencial humano universal suscita esse sentido, sendo uma capacidade comum a todos os seres humanos que os garante merecedores de respeito. A política da diferença, por sua vez, fundamenta-se num potencial humano a fim de desenvolver a própria identidade de cada indivíduo e para cada cultura (TAYLOR, 1998). Dessa forma, as políticas baseadas na noção do igual respeito conflitam-se, pois demandam um tratamento que, simultaneamente, reconheça as particularidades, mas que, ao mesmo tempo, ignore as diferenças.

Para Taylor a dependência dos outros influi na unidade de um projeto comum:

Uma reciprocidade perfeitamente equilibrada remove o espinho da nossa dependência da opinião dos outros e torna-se compatível com a liberdade. Isto, porque a reciprocidade completa, juntamente coma unidade de objetivo daí resultante, assegura que, ao seguir a opinião dos outros, não estou a ser, de modo algum, forçado a sair de mim mesmo. Continuo a obedecer-me 
como um membro deste projeto comum ou vontade geral. Neste contexto, dar importância à estima é compatível com a liberdade e com a unidade social, porque a sociedade é um espaço uno, onde todos os virtuosos serão incentivados de igual modo e pelas mesmas razões (certas). (TAYLOR, 1998, p. 68).

Não obstante a concepção iluminista de liberdade e de universal igualdade, não se pode olvidar, segundo Taylor, que a ausência de diferenciação e um objetivo comum aparecem com um projeto que não pode ser tomada de forma separada. Ou seja, a igualdade de estima exige uma unidade coesa de objetivo aparentemente incompatível com a diferenciação. Enquanto a era da dignidade anseia para que todos os cidadãos sejam igualmente honrados, a luta pelo reconhecimento apregoa uma solução de satisfatório reconhecimento entre iguais. Taylor protesta contra as alternativas liberais que acham os direitos individuais devam ser protegidos em primeiro lugar, ao aduzirem que as disposições de não discriminação devem ter prioridade sobre os objetivos coletivos.

A sociedade liberal não segue o esforço substancial, visto que realiza a adesão por um esforço processual tratando os indivíduos com igual respeito. Essa visão kantiana entende a dignidade humana como a autonomia, a capacidade de cada pessoa determinar para si mesma uma concepção de vida boa, e a associa ao poder de cada um para considerar e adotar uma perspectiva para si. A visão do ser humano como sujeito de escolhas autoexpressivas e determinante tem popularidade e explica a força do modelo de liberalismo. Charles Taylor assevera que uma sociedade liberal deve permanecer neutra em relação à noção de boa vida e coibir-se em assegurar uma relação justa entre os cidadãos, de modo que o Estado trate todos igualmente. Uma sociedade liberal caracteriza-se pelo modo como trata as minorias e pelos direitos que confere aos seus membros. Sendo assim, uma sociedade com objetivos fortes pode ser liberal desde que seja capaz de respeitar as diversidades e possa proporcionar as garantias adequadas aos direitos fundamentais (ARAUJO, 2004).

Nesse sentido, Taylor salienta que se devem distinguir, por um lado, as liberdades fundamentais, que não podem ser violadas e devem ser consolidadas e, por outro lado, os privilégios e as imunidades, que podem ser reduzidos por razões de política pública. A política do igual respeito é hostil à diferença, pois insiste na aplicação uniforme das regras que definem o liberalismo de direitos e não se ajusta à sobrevivência 
aspirada pelos membros de sociedades distintas. Existem modelos de sociedade liberal, apoiados em juízos de valor sobre uma vida boa, que pressupõem a defesa constante de certos direitos e se dispõem a dar maior importância ao tratamento uniforme à custa de uma sobrevivência cultural e, por vezes, preferir por essa. Assim, a política do igual respeito pode ser imaculada da acusação de que pretende homogeneizar as diferenças, mas existe outra maneira de ordenar uma acusação mais difícil de contestar. Embora não seja aconselhável, essa acusação advém do anseio por um terreno neutro, proporcionado pela política do igual respeito, em que todos os grupos possam conviver harmonicamente.

Para o autor, o liberalismo não almeja a neutralidade cultural completa. Taylor explica que o liberalismo não é uma referência capaz de promover o encontro de todas as culturas, porém é uma expressão política das variadas culturas, ora ajustada, ora incompatível com as outras. A exigência por reconhecimento reclama que seja reconhecido o valor igual das culturas, para se defenderem, sobreviverem e terem recebido seu mérito. Nesse meio, a inovação consiste na exigência pela divulgação da ideia do reconhecimento essencial à formação do sujeito.

Assim, em uma sociedade que se complexifica e que aumenta sua dose de multiculturalidade, torna-se imperioso encontrar formas democráticas que potencializem políticas de coexistência harmônica entre as diferenças. Entre a reivindicação por reconhecimento do valor igual e o encerramento nos critérios etnocêntricos da diferença, devem ser privilegiadas, segundo Taylor, as construções locais, as proposições de cunho comunitário. A base no valor igual exige adaptação ao estudo comparativo das culturas e empenho à abertura dos horizontes nos encontros multiculturais. Contundente é a afirmação de Taylor acerca do valor da igualdade:

$\mathrm{O}$ ato de declarar as criações de outra cultura como possuindo o mesmo valor e o ato de se declarar a favor dessas criações, mesmo que não sejam tão impressionantes, tornam-se indistintos. A diferença está só na embalagem. No entanto, o primeiro ato é entendido como uma expressão genuína de respeito, ao passo que o segundo é visto como um ato de paternalismo intolerável. Os supostos beneficiários da política do reconhecimento, ou seja, as pessoas que realmente poderiam beneficiar com a aceitação, fazem uma distinção cruel entre os dois atos. Elas sabem que o que desejam é respeito, não a condescendência. Qualquer teoria 
que elimine essa distinção parece distorcer aspectos decisivos da realidade que pretende consagrar. (TAYLOR, 1998, p. 90).

Nesse sentido, Charles Taylor critica a tese do liberalismo que concebe a sociedade como um agrupamento de indivíduos, cada qual com sua peculiar visão de vida boa e com direitos individuais universais que se impõem prioritariamente. Taylor ressalta que os laços comunitários de pertença dão sentido à vida dos indivíduos, tendo em vista que, a partir do diálogo com os "outros-importantes", a identidade cultural é traçada e os vínculos de afinco ao grupo se tornam perceptíveis e necessários para uma reciprocidade harmônica, para a conservação da comunidade e para a formação de uma consciência de si como um sujeito pertencente à comunidade.

\section{Em defesa da interculturalidade dos Direitos humanos: sobre a necessidade de se superar o debate entre liberais e comunitaristas}

Se o mal do liberalismo é desconsiderar as peculiaridades históricas de cada comunidade no reconhecimento de direitos específicos, alimentando uma cultura individualista de baixa integração entre seus integrantes e eliminando as condições materiais de desenvolvimento da identidade de cada indivíduo, os perigos das alternativas comunitaristas para a universalidade dos direitos humanos também não devem ser desconsiderados. Encerradas em si mesmas, tendem para o isolamento, para a afirmação de políticas de exclusão do diferente e para a formação de reclamos sustentados em práticas xenofóbicas, em nome de uma coesão social construída por relações de poder - político e militar - que se configuram em uma espécie de ditadura comunitarista (TOURAINE, 1999; LAPORTA, 1995). Se a comunidade permite o acesso do homem ao mundo de significações, como alegam os comunitaristas, não é menos verdadeiro que é a humanidade comum do homem - marca que permite o diálogo intercultural, o diálogo entre diferenças que se reconhecem mutuamente a partir de traços comuns - que faz da comunidade um âmbito de manifestação das particularidades e das diferenças, que também marcam a ideia de universalidade da humanidade. 
Ao que parece, o problema da universalidade dos direitos humanos na sociedade multicultural tem sido enfrentado por liberais e comunitaristas, cada um a seu modo, sem que se tenha explorado todas as possibilidades de não contradição entre particularismo, pluralismo, diversidade e universalidade (MARTÍNEZ-PUJALTE, 1998). De fato, a premissa básica dos direitos humanos, referenciada desde os jusnaturalistas, destaca que eles se constituem como ideiasforça, ou seja, fortalecem-se quando são violados, não perdendo suas características mesmo quando negados com base em atos culturais. Assim, a construção de uma teoria justificadora que fundamente e situe os direitos humanos diante de sistemas e práticas morais diversas, supõe a superação da dicotomia universalidade/diferença, universalismo/ particularismo, na busca de valores compartilhados, de valores e de direitos humanos que situam sua validade na humanidade do homem como tal, independentemente de qualquer tipo de vínculo de pertença (ZACCARIA, 2003).

Ao posicionar os sujeitos como pertences de uma mesma identidade, estabelecendo as bases de pertença para com o seu semelhante, a relação da cultura com o direito tende a ser inevitavelmente uma relação que demanda reconhecimento por sua diferença em relação às outras culturas, na intenção de satisfazer suas necessidades internas e de reproduzir seu modelo de identidade e, portanto, de diferença em relação aos outros. Com isso, todo o reclamo por identidade é, nesse caso, um reclamo por constituir os limites jurídicos que resguardam essa mesma diferença da interferência dos outros não-semelhantes, a qual requer uma proteção especial. Nessas circunstâncias, querer não participar de uma comunidade, ou querer participar dela na condição de diferente - na verdade, é sempre na condição de diferente -, são interesses que poderão colidir e, por consequência, produzir soluções inevitavelmente excludentes e discriminatórias, as quais são inconcebíveis pela universalidade dos direitos humanos (SEOANE, 1998).

A tarefa dos direitos humanos, nesse cenário, é a de estabelecer os exatos limites da igualdade e da diferença entre os indivíduos e entre as culturas, sem, contudo, negar os aspectos comuns que os identificam na qualidade de sujeitos particulares. Numa sociedade multicultural, esse desafio configura-se ainda maior, pois, enquanto as múltiplas identidades culturais existentes em um país postulam o direito de manifestarem sua especificidade nas mesmas condições, os direitos humanos devem 
tutelar apenas as diferenças que não sufocam sua missão de garantir a todos os homens como tais, e não na finalidade de integrantes dessa ou daquela cultura, os direitos necessários ao exercício de sua liberdade e autonomia. Eis então a questão: é possível sustentar a legitimidade de toda e qualquer cultura sem esvaziar a virtude universalista dos direitos humanos? Ou, em outras palavras, é possível defender a universalidade dos direitos humanos sem atacar toda a espécie de relativismo que nega a possibilidade de fundamentar tais direitos na humanidade comum de cada homem? Enfim, até que ponto universalidade e particularismo não se opõem?

A universalidade dos direitos humanos não tolera toda nem qualquer forma de particularidade cultural (RUIZ-GALVEZ, 1999; 1997). Garantir o mesmo tratamento para as diferentes culturas e demandas identitárias, independentemente da substancialidade normativa e ética de cada uma delas, importa em defender de modo ilimitado à diferença e o particularismo, e mais, acabar com o papel crítico e propositivo dos direitos humanos. Se todo particularismo é considerado igualmente moral, se cada sociedade produz sua concepção válida de moral crítica, conceitos como violência, liberdade e solidariedade perdem toda a sua força referencial para uma análise universal desses temas. A universalidade dos direitos humanos, não custa lembrar, é de direito e não de fato e, portanto, suas exigências permanecem intactas mesmo quando na prática as comunidades particulares não os cumprem (CAMPS, 1996).

Por isso, se os direitos humanos não puderem ser apresentados como um conjunto de exigências recíprocas que se deve aos homens e aos Estados, independentemente de sua posição geográfica, econômica, política e também cultural, de discursos e práticas ditatoriais, de preconceitos de todas as ordens, de costumes ofensivos à dignidade humana e outras ações aviltantes. Eles serão sempre legitimados pelas moralidades dominantes, moralidades locais, reproduzindo-se as realidades que os direitos humanos visam a enfrentar. A questão não é, como se disse, reconhecer e aceitar as diferenças culturais que traduzem as formas particulares de se produzir pertença digna no mundo. Tomada nesses termos, a diversidade se constitui como fonte de inventividade e de renovadas riquezas autênticas que merecem proteção. O problema reside em práticas culturais que aviltam, que impõem um comportamento indesejado para uma parcela dessa mesma cultura, funcionando como mecanismo de poder e de autoridade hierárquica. 
As lutas em prol das diferenças não podem ocorrer isolandoas cada vez mais do encontro com as igualdades e peculiaridades que marcam o outro da mesma ou diferente cultura. Nesse diálogo, não são as marcas as quais afastam que deveriam importar, mas são os pontos que convergem para uma humanidade comum, centrada na reciprocidade de exigências, que deverão compor a agenda de responsabilidades de todos. Ao desistirem de procurar o indivíduo como sujeito moral, os comunitaristas aumentaram o abismo entre as diferenças que, por exigirem reconhecimento específico, cumprem quase exclusivamente com o papel de construir a identidade do sujeito como membro de uma determinada coletividade. Não há, nas condições comunitaristas, espaço para a dignidade humana, mas apenas para uma dignidade da cultura, apresentada, então, como pré-condição da própria individualidade. Abusando da metáfora, é como se víssemos mais índio no homem que homem no índio; que judeu nos dissesse algo bem mais significativo que homem. Todos conhecemos o legado e os riscos das uniformizações que sufocaram a autonomia moral do sujeito em prol da cultura, religião, nacionalidade, raça etc.

Mas o problema das diferenças também não foi plenamente respondido pelos liberais radicais ou mesmo pelo culturalismo liberal. Se no comunitarismo o perigo é caracterizado pelo potencial isolamento das culturas entre si, nas tendências liberais a falta de solidariedade entre os indivíduos e a universalidade abstrata são apontadas como fragilidades substanciais para a condução satisfatória dos projetos de vida coletivos e para a proteção das minorias. Certamente que os direitos de um indivíduo necessitam de condições objetivas de efetivação, entre as quais o fator econômico se encontra em posição de destaque. Por isso, a dignidade e a liberdade dos indivíduos não serão automaticamente garantidas sem que exista um favorável cenário material para tanto não basta uma posição de neutralidade e de não-intervenção por parte do Estado ou dos outros cidadãos. Ao retratarem o sujeito em uma condição de pura idealidade, as posições liberais correm o risco de reproduzir uma universalidade homogeneizadora, que desconsidera as diferenças importantes que constituem o homem em sua humanidade, seus vínculos sociais e sua existência material; que deixa de lado, segundo Juan Carlos Arroyo (2000), a dimensão supraindividual do ser humano, esquecendo-se que o próprio processo de individualização se perfaz por meio da socialização com outros sujeitos. 
Não se trata, então, como já se afirmou, de defender uma universalidade uniformizadora ou um particularismo desigualizador (SOUSA, 2003). É na interculturalidade que os direitos humanos depositam sua fonte de legitimidade ética e sua força política. Ao mediar doses de comunitarismo no individualismo e vice-versa, o intercultualismo viabiliza a formação de novos consensos, de diálogos que contemplam a presença da riqueza da historicidade sem, contudo, sonegar a autonomia e a liberdade igual de todos os indivíduos (HABERMAS, 2002; APEL, 2000).

Para contrapor o relativismo à universalidade abstrata, Christoph Eberhard (2004, p. 167) sugere a adoção de um "pluralismo saudável”, baseado em um "diálogo mútuo que permite que descubramos respectivamente aos outros e a nós mesmos, e que descubramos o passado e o presente de ambos, construindo juntos um futuro comum”. Um diálogo intercultural sobre os direitos humanos, portanto, não pode ser interpretado como uma postura totalmente relativista, ou como negativa da universalidade ou da importância de tais direitos. Segundo o autor, "a questão não é desconstruir a abordagem ocidental refutando sua universalidade, mas sim enriquecê-la por meio de perspectivas culturais diferentes, com vistas a avançar progressivamente rumo a uma práxis intercultural dos direitos humanos e abrir novos horizontes para uma boa vida para todas as pessoas" (EBERHARD, 2004, p. 161). O diálogo entre as culturas permite a formação de novos horizontes e predispõe o homem a olhar e a escutar os outros, alterando suas concepções sobre o mundo, o que é condição indispensável para a coexistência pacífica. É preciso entender, de acordo com Montiel (2003, p. 43), que, da mesma forma que os antepassados "se adaptaram às circunstâncias do mundo que os rodeava, nós também deveremos abrir-nos às culturas de hoje. Somente por meio de um intercâmbio fluido teremos a possibilidade de encontrar novas soluções para nossas diferenças culturais". O encontro com as outras culturas tende a contribuir para a formação de projetos que se enriquecem mutuamente, bem como permite conhecer as virtudes presentes no outro e encontrar as semelhanças que permitem a definição de uma pauta comum de preocupações que será a base para as conversações.

Por isso, o diálogo intercultural é antes uma exigência ética do que geopolítica, pois sua agenda de preocupações está centrada na semelhança das demandas que perpassam todas as culturas, e não nas 
postulações setoriais de uma dada cultura em particular. Como uma reivindicação ética, o diálogo entre as culturas, anota acertadamente August Arazo (1992, p. 163), “comporta también la exclusión de todo fanatismo y autocomplacencia. (...) Se trata, en definitiva, de hacer posible una comunicación libre y sincera que conduzca a una acción solidaria y creativa. Solamente sobre tal base los derechos humanos pueden adquirir su sentido pleno". Assim, a interculturalidade deve ser entendida como uma alternativa para a coexistência das diferentes culturas, porque permite o reconhecimento do direito à diferença sem corroborar as práticas políticas assimilacionistas e de segregação e sem promover a perda dos elementos constituidores de cada cultura, permitindo que a união das semelhanças que brotam do diálogo entre as culturas e a formação de novos consensos contribuam para o surgimento de um novo modelo (CORELLA, 1998).

O diálogo intercultural visa a identificar, nas diferentes culturas, os traços de humanidade que dizem respeito à existência digna do homem, independentemente da cultura, nação, religião ou outro vínculo. Assim, por exemplo, são considerados valores universais a dignidade humana, a identidade, a liberdade de ser e de estar, a inviolabilidade do corpo, o bem-estar humano, entre outros. Isso, como já se disse, não implica a promoção de uma homogeneização das práticas culturais num universalismo abstrato que nega a diferença, mas a compreensão dos atributos humanos comuns que perpassam todas as existências individuais e que devem ser reconhecidos reciprocamente como necessários à convivência pacífica. A humanidade comum do homem não quer dizer que todas as culturas e sujeitos particulares estejam fadados a uma história comum, com conceitos, práticas, hábitos e mesmo valores uniformes. Por óbvio que isso não teria sentido e a realidade bem demonstra isso. É sabido que existem características morais que dão o tom da humanidade comum presente em cada ser humano, as quais se manifestam de diferentes maneiras nas comunidades culturais particulares, que produzem, cada uma a seu modo, suas regras e seus conceitos. O homem, para além dos traços da espécie, também apresenta elementos comuns no que tange à sua dependência formativa da cultura e no que se refere a sua individualidade reflexiva. É essa humanidade comum, então, presente em cada um de nós e em cada manifestação cultural específica, que deve fomentar o diálogo entre as culturas e 
promover o reconhecimento intercultural de um conjunto de obrigações recíprocas que se devem os homens para poder coexistirem dignamente.

De fato, é preciso superar o multiculturalismo de justaposição, que inevitavelmente leva a construção de isolamento, de guetos étnicos que tendem a proliferar rivalidades. Em uma sociedade em que as diferenças são cada vez mais aparentes e desafiadoras do consenso, não é de bom alvitre que as janelas de cada cultura se fechem e impeçam olhares de fora para dentro e de dentro para fora. Não devem ser tomadas como moralmente aceitáveis as alternativas comunitaristas que sufocam a autonomia e a liberdade do indivíduo na condução da vida segundo suas escolhas críticas, como também não são desejáveis as soluções liberais que aniquilam o indivíduo ao universalizá-lo abstratamente, ao retirá-lo do mundo real das influências e trocas culturais. Nesse sentido, o papel dos direitos humanos é permitir que todos os homens, em igualdade de condições, acessem o mundo com liberdade e dignidade, independentemente dos vínculos culturais que possuam. Sua missão, então, é a de promover um diálogo intercultural que fortaleça, em escala global, as demandas comuns do homem e as instituições democráticas para resolvê-las, facultando uma conversação na qual todos os interessados, culturas e indivíduos, possam, em igualdade de condições, manifestar as suas preocupações e as suas diferenças, na busca de respostas para os problemas que são interculturais.

\section{Considerações Finais}

Apesar de a efetivação dos direitos humanos e mesmo sua definição material estarem diretamente vinculadas à realidade histórica de uma comunidade, isso não quer dizer que o fundamento desses direitos deve estar necessariamente vinculado à história dessa mesma comunidade. Os direitos humanos não podem ser explicados e fundamentados em si mesmos, mas na universalidade que constitui o homem como tal. Assim como não se pode fundamentar o direito positivo em si mesmo, mas sim em interesses e valores de várias ordens, os direitos humanos pretendem retratar o que é universalmente indispensável ao homem, independentemente de sua identidade cultural. Antes de ter uma identidade cultural que lhe dá uma perspectiva de estar no mundo, uma 
identidade e uma pertença, o homem é refém de sua própria posição humana, que é universal, pressuposto para a afirmação de seus sentidos individuais e de grupo (FERNÁNDEZ, 2003).

Se a teoria dos direitos humanos cultivar e defender sectarismos e relativismos de qualquer ordem, os problemas do mundo não passarão de problemas de Estado ou de uma cultura, problemas objetivados na percepção pura e simples das necessidades básicas e circunstanciais de cada grupo isolado. Numa sociedade multicultural, permeada por diferentes identidades, os direitos humanos devem ser o referencial comum para um diálogo intercultural, capaz de aproximar as diferenças e de reconhecê-las em sua perspectiva histórica. Como se disse, não se trata de uma universalização uniformizadora, mas sim de uma "universalidade moderada", que poderá mediar as diferenças e servir de ponto de partida ético para uma cultura de tolerância e de emancipação que reconheça as identidades sem ofuscar e negar aquilo que é reclamado pela condição humana universal, por todos os povos e por todas as culturas.

Essa estratégia pelos direitos humanos é condição, inclusive, para a manutenção das próprias diferenças identitárias, pois caso contrário à relativização de tudo e de qualquer valor poderá permitir o avanço de uma cultura particular sobre a outra. A prática nazista de igualização ou de indiferenciação humana, proposta de modo uniforme nos campos de concentração, por exemplo, retrata o perigo que pode representar o domínio de uma percepção histórica, o perigo que está demarcado em um relativismo uniformizador. Negar a diferença pode ser tão desastroso para a democracia como negar a universalidade da condição humana. A universalidade dos direitos humanos, nesse caso, antes de ser obstáculo, é condição para o desenvolvimento, reconhecimento e tolerância das identidades e das culturas que respeitam as outras culturas e que garantem para os seus integrantes o direito de exercerem sua individualidade autonomamente. O que se percebe, inclusive, é que a universalidade dos direitos humanos permite que sejam reconhecidas muitas culturas que seriam negadas se não existissem determinados direitos específicos que protegem certas diferenças. Assim, ao reconhecer a humanidade comum de todos os homens, as diferenças e os particularismos adquirem sentido pelo recurso aos direitos humanos, que identifica aquelas condições que não podem ser pluralizadas e tampouco legitimidades pelo argumento historicista (HÖFFE, 2000). 
Um diálogo intercultural, nesse contexto, poderá representar uma abertura para processos de conhecimento recíproco que, mesmo que opere de modo tenso e conflituoso, produz encontros de diferenças e de igualdade que tendem a se reconhecer ou se rejeitar. Esse choque de estranhamento é inevitável quando se está diante do novo e do inusitado, na leitura de culturas diferentes. Todavia, é preciso ter clareza que interculutalidade não pode ser entendida como sendo a condição de possibilidade da formação de um acordo semântico em torno de conceitos, uma espécie de consenso fundante do diálogo. Interculturalidade deve ser tomada como um momento de alteridade, no qual as diferentes culturas sem percebam, se reconheçam e se diferenciam tomando por base elementos comuns e compartidos entre elas. Em outras palavras, a diferença de uma cultura somente é percebida internamente pelos seus "eus" semelhantes quando em contato com os "outros" de culturas diferentes. Assim, o diálogo intercultural é indispensável para que as diferenças sobrevivam, mas sobretudo para que o diálogo entre a igualdade e diferença entre as culturas seja mediado por formas não arbitrárias e fundamentalistas de produzir a pertença e a identidade, como se os direitos humanos pudessem ser completamente subjugados pelo direito das culturas distintas fazerem o que desejarem internamente contra o seus componentes. Por fim, é necessário ficar alerta para o risco, sempre presente, de a universalidade sem moderações converter-se em homogeneização ou de o direito à diferença propagar desigualdade. A interculturalidade dos direitos humanos tem substancialidade suficiente para desempenhar os limites mediadores entre a igualdade e a diferença e impedir a formação de novos fundamentalismos baseados na negação da igualdade e/ou na negação da diferença. 


\section{REFERÊNCIAS}

ALCALÁ, J. Alberto del Real. Problemas de gestión de la diversidad culturalen un mundo plural. In: RUIZ, Ruiz Ramón; etal. (Editores). Derechos fundamentales, valores $\mathrm{y}$ multiculturalismo. Madrid: Dykinson, 2005.

ALTABLE, Maria Pilar González. Liberalismo vs. Comunitarismo (John Rawls: una concepción política del bien). In: Doxa. Cuadernos de Filosofía del Derecho. Alicante: Universidad de Alicante; Biblioteca Digital Miguel Cervantes, n.s 17-18, 1995, pp.117-136.

ÁLVAREZ, Silvina. La racionalidad de la moral. Un análisis crítico de los presupuestos morales del comunitarismo. Madrid: Centro de Estudios Políticos y Constitucionales, 2002.

APEL, Karl-Otto. O problema do multiculturalismo à luz da ética do discurso. In: ETHICA-Cadernos Acadêmicos. v. 7. Rio de Janeiro, 2000.

ARAZO, August Monzon I. Derechos humanos y diálogo intercultural. In: BALLLESTEROS, Jesús (Editor). Derechos humanos. Concepto, fundamentos, sujetos. Madrid: Tecnos, 1992.

ARROYO, Juan Carlos Velasco. Derechos de las minorías y democracia liberal: un debate abierto. In: Revista de Estudios Políticos. Madrid: Nueva Época. n. 109, Julio-Septiembre de 2000.

BICK, Mimi. El debate entre liberales y comunitaristas. Santiago de Chile: Universidad Nacional Andrés Bello, 1995.

CAMPS, Victoria. La universalidad y sus enemigos. In: GINER, S.; SCARTEZZINI, R. (Editores). Universalidad y diferencia. Madrid: Alianza Editorial, 1996.

COLOZZI, Ivo. Ciudadanía y bien común en la sociedad multiétnica y multicultural. In: Persona y Derecho. Pamplona: Universidad de Navarra, n. 49, 2003.

CORELLA, Ángeles Solanes. Una respuesta al rechazo racista de la inmigración: La interculturalidad. In: Anuario de filosofía del derecho. Madrid: Nueva Época. Tomo XV, 1998.

DÍAZ, Francisco Javier de la Torre. El modelo de diálogo intercultural de Alasdair MacIntyre. El diálogo entre las diferentes tradiciones. Madrid: Dykinson, 2001.

DULCE, María José Fariñas. Los derechos humanos: desde la perspectiva sociológico-jurídica a la "actitud postmoderna". Madrid: Dykinson, 1997.

EBERHARD, Christoph. Direitos humanos e diálogo intercultural. Uma perspectiva antropológica. In: BALDI, César Augusto (Org.). Direitos humanos na sociedade cosmopolita. Rio de Janeiro: Renovar, 2004. 
FERNÁNDEZ, Encarnación. Igualdad y derechos humanos. Madrid: Tecnos, 2003.

GREBLO, Edoardo. A misura del mondo. Globalizzazione, democracia, diritti. Bolonia: Il Mulino, 2004.

HABERMAS, Jürgen. A inclusão do outro. Estudos de teoria política. Tradução de George Sperber e Paulo Astor Soethe. São Paulo: Loyola, 2002,

HÖFFE, Otfried. Derecho intercultural. Traducción de Rafael Sevilla. Barcelona: Gedisa, 2000.

JULIANO,Dolores. Universal/particular. Un falso dilema.In: BAYARDO, Rubens; LACARRIEU, Mónica (Comp.). Globalización e identidad cultural. 2. ed. Buenos Aires: Ediciones Ciccus, 1998.

KYMLICKA, Will. Ciudadanía multicultural. Una teoría liberal de los derechos de las minorias. Traducción de Carme Castells Auleda. Barcelona: Paidós, 1996.

. Estados, naciones y culturas. Traducido y adaptado por Juan Jesús Mora. Córdoba: Editorial Almuzara, 2004.

La política vernácula. Nacionalismo, multiculturalismo y cidadania. Traducción de Tomás Fernandéz Aúz y Beatriz Eguibar. Barcelona: Paidós, 2003.

- Liberalism, Community, and culture. Oxford: Oxford University Press, 1989.

. Multiculturalismo Liberal e direitos Humanos. In: SARMENTO, Daniel; IKAVA, Daniela; PIOVESAN, Flávia. Igualdade, diferença e Direitos Humanos. Rio de Janeiro: Lumen Juris, 2008.

STRAEHLE, Cristiane. Cosmopolitismo, Estado-nación y nacionalismo de las minorías. Un análisis crítico de la literatura reciente. México: Universidad Autónoma de México, 2001.

. Filosofia política contemporânea. Tradução de Luís Carlos Borges. 1. ed. São Paulo: Martins Fontes, 2006.

LA FUENTE, Oscar Pérez de. La polémica liberal comunitarista. Paisajes después de la batalla. Cuadernos "Bartolomé de las Casas" 35. Madrid: Dykinson, 2005.

Pluralismo cultural y derechos de las minorías. Una aproximación iusfilosófica. Madrid: Dykinson, 2005.

LAPORTA, Francisco J. Comunitarismo e nacionalismo. In: Doxa. Cuadernos de Filosofía del Derecho. Alicante: Universidad de Alicante; Biblioteca Digital Miguel Cervantes, n. 17-18, 1995, p. 53-68.

LÓPEZ, Eduardo Riveira. Las paradojas del comunitarismo. In: Doxa. Cuadernos de Filosofía del Derecho. Alicante: Universidad de Alicante; Biblioteca Digital Miguel Cervantes, n. 17-18, 1995. p. 95-115. 
LUCAS, Doglas Cesar. Direitos humanos e interculturalidade. Um diálogo entre a igualdade e a diferença. 2.ed. Ijuí: Unijuí, 2013.

MACINTYRE, Alasdair. Depois da virtude. Um ensaio em teoria moral. Tradução de Jussara Simões. Bauru, SP: EDUSC, 2001a, p. 127.

- Justiça de quem? Qual racionalidade? Tradução de Marcelo Pimenta Marques. 2. ed. São Paulo: Loyola, 2001b, p. 371.

MALDONADO, Daniel Bonilla. La constitución multicultural. Bogotá: Siglo del Hombre; Pontificia Universidad Javeriana; Universidad de los Andes, 2006.

MARTÍNEZ-PUJALTE, Antonio-Luis. Derechos humanos e identidad cultural. Una posible conciliación entre interculturalidad y universalidad. In: Persona y Derecho. Pamplona: Universidad de Navarra, n. 38, 1998.

MASSINI CORREAS, Carlos Ignácio. Liberalismo, comunitarismo, realismo: en busca de la tercera via. In: Sapientia. Buenos Aires. v. 56. n. 210, pp. 549-564.

MIGUEL, Alfonso Ruiz. Derechos humanos y comunitarismo. Aproximación a un debate. In: Doxa. Cuadernos de Filosofía del Derecho. Alicante: Universidad de Alicante; Biblioteca Digital Miguel Cervantes, n. 12, 1992, pp. 95-114.

MONTIEL, Edgar. A nova ordem simbólica: a diversidade cultural na era da globalização. In: SIDEKUM, Antônio (Org.). Alteridade e multiculturalismo. Ijuí: Unijuí, 2003.

OLIVÉ, León. Multiculturalismo y pluralismo. Paidós: México, 1999.

OLSEN, Teresa Cristina Tschepokaitis. Uma introdução ao debate acerca da fundamentação dos direitos humanos: liberalismo versus comunitarismo. Revista Direito, Estado e Sociedade. v. 9, n. 24, jan./jun. 2004, pp. 112-136.

PAREKH, Bhikhu. Repensando el multiculturalismo. Diversidad cultural y teoría política. Traducción de Sandra Chaparro. Madrid: Istmo, 2000.

PEDREIRA, Elena Beltrán. Diversidad y deberes cívicos: liberalismo, ciudadanía y multiculturalismo. In: DÍAZ, Elías; COLOMER, José Luis. Estado, justicia, derechos. Madrid: Alianza Editorial, 2002.

PINILLA, Julio Seoane. Comunitarismo. Multiculturalismo. Un comentario. In: Doxa. Cuadernos de Filosofía del Derecho. Alicante: Universidad de Alicante; Biblioteca Digital Miguel Cervantes, n. 20, 1997, pp. 377-390.

RAWLS, John. O liberalismo político. Tradução de Dinah de Abreu Azevedo. 2. ed. São Paulo: Ática, 2000.

RAZ, Joseph. La ética en el ámbito público. Traducción de Maria Luz Melon. Barcelona: Gedisa, 2001. 
RUIZ, Ruiz Ramón. Liberalismo y comunitarismo: dos perspectivas antagónicas del fenómeno multicultural. In: RUIZ, Ruiz Ramón; et al. (Editores). Derechos fundamentales, valores y multiculturalismo. Madrid: Dykinson, 2005.

RUIZ-GALVEZ, Maria Encarnación Fernández. Del universalismo abstracto a la universalidad concreta. In: Persona y Derecho. Pamplona: Universidad de Navarra, n. 41, 1999.

. Derechos humanos: ¿Yuxtaposición o integración? In: Anuario de Filosofía del Derecho. Madrid: Nueva Época, n. IX, 1997.

SANCHÉS-CÁMARA, Ignácio. El comunitarismo y la universalidad de los derechos humanos. In: Persona y Derecho. Pamplona: Universidad de Navarra, n. 38, 1998.

.Estado laico y sociedad multicultural. In: Sociedad multicultural y derechos fundamentales. Madrid: Consejo General de Poder Judicial, 2007.

SANDEL, Michael. O liberalismo e los limites da justicia. Lisbos: Calouste Gulbenkian, 2005.

SANTOS, Boaventura de Sousa. Por uma concepção multicultural dos direitos humanos. In: SANTOS, Boaventura de Sousa (Org.). Reconhecer para libertar: os caminhos do cosmopolitismo multicultural. Rio de Janeiro: Civilização Brasileira, 2003.

SEMPRINI, Andrea. Multiculturalismo. Tradução de Laureano Pelegrin. Bauru: EDUSC, 1999.

SORIANO, Ramón. Interculturalismo. Entre liberalismo y comunitarismo. Córdoba: Almuzara, 2004.

TAYLOR, Charles. A política de reconhecimento. In: TAYLOR, Charles; et al. Multiculturalismo - examinando a política de reconhecimento. Lisboa: Piaget, 1998.

. Argumentos filosóficos. Tradução de Adail Ubirajara Sobral. São Paulo: Loyola, 2000.

As fontes do self. A construção da identidade moderna. Tradução de Adail Ubirajara Sobral e Dinah de Abreu Azevedo. São Paulo: Loyola, 1997.

TORRE, Giuseppe Dalla. La multiculturalità come dato di fatto e come programma etico-politico. In: TORRE, Giuseppe Dalla; D’AgOSTINO, Francesco (Orgs.). La cittadinanza. Problemi e dinamiche in una società pluralística. Torino: G. Giappichelli Editore, 2000.

TOURAINE, Alain. Poderemos viver juntos? Iguais e diferentes. Tradução de Jaime A. Clasen e Ephairaim F. Alves. Petrópolis: Vozes, 1999.

VITALE, Ermanno. Liberalismo e multiculturalismo. Una sfida per il pensiero democratico. Roma-Bari: Laterza, 2000. 
WALZER, Michael. Comentário ao ensaio de Taylor. In: TAYLOR, Charles; et al. Multiculturalismo - examinando a política de reconhecimento. Lisboa: Piaget, 1998.

WALZER, Michael. Esferas de justiça. Uma defesa do pluralismo e da igualdade. Tradução de Jussara Simões. São Paulo: Martins Fontes, 2003.

Doglas Cesar Lucas

Pós-doutor em Direito pela Università degli Studi Roma Tre, Itália. Doutor em Direito pela UNISINOS e Mestre em Direito pela UFSC. Professor nos cursos de Graduação e no Mestrado em Direito da UNIJUÍ. Professor no Curso de Graduação em Direito do Instituto Cenecista de Ensino Superior de Santo Ângelo - IESA. Professor visitante do mestrado em direito da URI - Santo Ângelo. Avaliador MEC/INEP.

Líder do Grupo de Pesquisa no CNPQ Fundamentos e concretização dos Direitos Humanos.

doglasl@unijui.edu.br.

http://lattes.cnpq.br/1332521470619712 